This document is the accepted manuscript version of the following article:

Tarpoudi Baheri, F., Schutzius, T. M., Poulikakos, D., \& Poulikakos, L. D. (2020). Bitumen surface microstructure evolution in subzero environments. Journal of Microscopy. https://doi.org/10.1111/jmi.12890

\title{
Bitumen surface microstructure evolution in sub-zero environments
}

\author{
F. Tarpoudi Baheri ${ }^{1,2}$, T. M. Schutzius ${ }^{2}$, D. Poulikakos ${ }^{2}$, L. D. Poulikakos ${ }^{1 *}$ \\ 1- Laboratory for Road Engineering/ Sealing Components, Empa, \\ Überlandstrasse 129, 8600 Dübendorf, Switzerland \\ 2- Laboratory of Thermodynamics in Emerging Technologies, Department of Mechanical and Process \\ Engineering, ETH Zurich, Sonneggstrasse 3, CH-8092 Zurich, Switzerland.
}

* Corresponding author, Email: lily.poulikakos@empa.ch

Keywords: asphalt, bitumen, AFM-IR, FTIR, microstructures, surface chemistry, sub-zero temperature

\begin{abstract}
Bitumen is a widely used material employed as a binder in pavement engineering and as a surface sealant in construction. Its surface microstructure and microscale properties have been shown to be temperature-dependent, with effects manifesting themselves on surface composition and texture, including the formation of the visually striking catana "bee"-like structures. Despite the importance of a good performance of bitumen in sub-zero environments $\left(<0{ }^{\circ} \mathrm{C}\right)$, the behavior of bitumen surface texture and composition at cold temperatures, affecting cracking, degradation, and road icing, has received practically no attention. In particular, such knowledge is relevant to world regions experiencing long periods of sub-zero temperatures during the year. Employing advanced atomic force microscopy combined with infrared spectroscopy (AFM-IR) and an environmental chamber, we demonstrate the ability to characterize surface structure and composition with nanoscale precision for a broad range of temperatures. We show that cooling bitumen to sub-zero temperatures can have several interesting effects on its surface micro-texture, nano-texture, and composition, especially on its three surface domains, catana, peri, and para. We found that the para domain coarsens and extends to form an interfacial transition domain (characterized by increasing surface roughness with peri domain composition) between the para and peri domains. We show that the catana and peri domains have a similar composition, but have different mechanical and chemical properties compared to the para domain. The essential findings of this work improve our understanding of the behavior of bitumen in sub-zero environments, aiding us in our quest towards attaining better road and sealant performance.
\end{abstract}

\section{Introduction}

Asphalt concrete is a composite material containing conventionally ca. $5 \%$ bituminous binder and ca. $95 \%$ mineral aggregates by weight ${ }^{1}$. Even though only a small percentage of the asphalt concrete

This article has been accepted for publication and undergone full peer review but has not been through the copyediting, typesetting, pagination and proofreading process, which may lead to differences between this version and the Version of Record. Please cite this article as doi: 10.1111/jmi.12890.

This article is protected by copyright. All rights reserved. 
weight fraction is bitumen, due to its binding role, bitumen is indispensable and is mainly responsible for the mechanical and viscoelastic properties of the asphalt concrete mixture ${ }^{1}$. Bitumen, a bi-product of crude oil, has a complex chemical makeup and should maintain its desirable properties over a range of temperatures and environmental conditions; this is an important aspect of pavement and sealant design ${ }^{2}$. Previous work has shown that the bitumen surface develops three distinct microstructural domains after annealing: The "bee" structure or catana domain is wrinkled, with hills and valleys, and owes its name to the Greek words: cato (low) and ano (high). The catana domain is surrounded by the waxy peri (Greek meaning "around") domain. The final domain is named para (Greek meaning neighboring) and is softer relative to the other domains ${ }^{3}$. The peri domain consists mostly of lightweight saturates (waxy, thin film in $\mathrm{nm}$ scale) ${ }^{4}$. Crystallization of lightweight waxy saturates (nheptane insoluble components ${ }^{5}$ ) on the surface during cooling creates a thin film ${ }^{6}$. Previous work showed that during cooling, the material surrounding and underlying the wax shrinks, compressing the film, and beyond a critical strain, forces it to buckle and to form wrinkles ${ }^{4,7,8}$. After exposure to high temperatures, the surface composition of bitumen can change ${ }^{9-12}$. The so-called "surface microstructures" ${ }^{4,13-18}$ and the properties of bitumen are also affected by temperature. Bitumen behaves like a Newtonian fluid above its melting point and as a viscoelastic material below it ${ }^{19,20}$. It consists of four main hydrocarbon fractions, saturates, aromatics, resins, and asphaltenes, each having different physiochemical and thermal properties ${ }^{21}$. These are termed SARA fractions, based on increasing molecular weight and molecular polarity ${ }^{21-27}$. Aromatics play an essential role in microstructure formation ${ }^{28}$. To date, the distribution of SARA fractions in the different surface domains of bitumen remains unclear.

Developing higher resolution microscopy techniques-especially chemical imaging-enable us to understand the complex surface chemistry and the rich surface microstructure of bitumen better. Previous works have used TOF-SIMS (time of flight secondary ion mass spectroscopy) to perform chemical characterization of bitumen based on molecular mass. While TOF-SIMS has excellent depth resolution (nanoscale) ${ }^{29}$, the main drawback of TOF-SIMS for imaging of bitumen is that it operates under vacuum, so to assure stability of a volatile sample like bitumen the sample is normally cooled to $-80^{\circ} \mathrm{C}$, which is far from the conditions of interest for many applications ${ }^{30,31}$. In comparison to AFM, it also has a lower resolution of $1 \mu \mathrm{m}$, which is not sufficient to capture all the chemical details of bitumen surface submicron-structures.

Other works on chemical imaging of bitumen used the s-SNOM (scattering-type scanning near-field optical microscopy) technique, which has a lateral resolution of $10 \mathrm{~nm}$ and a depth resolution of $\sim 1-$ $10 \mathrm{~nm}^{30,31}$. Previous reports that used s-SNOM to characterize bitumen found a distinguishable chemical difference between the para and peri domains and showed that concentrations of sulfoxide and carbonyl groups are different in the peri and para domains ${ }^{32}$; however, the IR spectra of these domains are not reported. The s-SNOM technique depends on the complex optical properties of the sample, tip, and underlying substrate of the sample to measures the amount of the scattered light from sample ${ }^{33}$. Therefore s-SNOM performs best on rigid materials that also efficiently scatter light. However, it is more challenging to characterize, soft and high coefficient light-absorber materials such as bitumen, with s-SNOM ${ }^{33}$, while materials with significant thermal expansion coefficient $\left(\alpha_{\text {exp }}\right)$ and small thermal conductivity are generally easy to measure with AFM$\mathrm{IR}^{34}$

The AFM-IR technique uses the quick and short local thermal expansion of the under investigation material recognized as a force impulse for the cantilever and drives the cantilever into simultaneous

This article is protected by copyright. All rights reserved. 
multiple oscillatory modes (i.e., Eigenmodes). The cantilever oscillation amplitude is directly proportional to the absorbed IR light amount and absorption coefficient ${ }^{33,35-37}$. The deflection of the cantilever in the AFM-IR technique provides a direct measurement of the absorbed light, and it provides some advantages in comparison to other techniques, as discussed in the sequel. AFM-IR is a model-free IR absorption spectroscopy without band distortions and peak shifts, and the results of this technique are suitable for the analytical characterizing of the chemical composition of organic and polymeric materials such as bitumen with an excellent correlation to conventional FTIR (Fouriertransform infrared spectroscopy) results ${ }^{33}$. A recently published study ${ }^{38}$ on bitumen using a similar AFM-IR device and sample preparation method reports on the chemical composition of the surface of bitumen at the nanoscale. Specifically, the authors report on topography maps, phase maps, functional group distribution maps, and infrared spectra of base bitumen samples before and after aging. The results strongly suggest that the chemical fractions of each phase on the bitumen surface are quite similar and have a higher polarity than that of the bulk material.

The main advantage of the AFM-IR technique in comparison to the ones mentioned above is that it allows investigating the chemical composition of the surface of bitumen with nanoscale resolution independent of surface complex optical properties and under environmental conditions that were more relevant for bitumen applications. Therefore, we chose the AFM-IR technique to perform cold temperature studies on bitumen samples in simulated winter conditions. The method has the potential to give insight into the mechanisms responsible for morphological and compositional changes of bitumen with temperature. Only a few works have investigated the relationship between surface topography and composition as a function of temperature. In addition, those that did, focus on high temperatures ${ }^{18,39-45}$ with limited knowledge existing for colder temperatures.

Here we show how the surface texture and composition of bitumen at the micro/nanoscale can undergo significant changes when cooled to sub-zero temperatures $\left(<0{ }^{\circ} \mathrm{C}\right)$. Employing AFM-IR, we observe a change in surface roughness at the para-peri interface during cooling, which we term the interfacial "transition" domain. We show that, chemically, the transition domain is similar to the para domain. We also show that within the para domain, certain island-like rougher features appear during cooling, which is termed "sal" sub-domain ${ }^{13}$. At high cooling rates, the para domain is rich in sal subdomains, but at slow cooling rates, the transition domain is dominant. The para domain was found to be chemically and mechanically distinct compared to the other surface domains. These findings advance our understanding of bitumen surface behavior, in particular as it relates to its use at cold climates.

\section{Materials and Methods}

\section{Materials}

We used bitumen of medium softness (penetration grade 70/100, EN 1426, from the Middle East origin). This bitumen contains natural wax, with a needle penetration of $82(0.1 \mathrm{~mm})$, a softening point of $45.8^{\circ} \mathrm{C}$, and dynamic viscosity of $163 \mathrm{~Pa}$-s at $60^{\circ} \mathrm{C}$. Inter-laboratory studies on this bitumen using differential scanning calorimetry (DSC) at heating/cooling rate of $10^{\circ} \mathrm{C} / \mathrm{min}$ have shown a glass transition temperature $\mathrm{Tg}$ of $\mathrm{ca}-20^{\circ} \mathrm{C}$ and a melting peak of ca $28^{\circ} \mathrm{C}$. The SARA factions reported are $3.8,59.6,22.2$, and 14.6 respectively ${ }^{45}$. The DSC results depend on the cooling rate as reported and discussed in the SI. 
The usual sample preparation methods for AFM studies of bitumen include heat ${ }^{46}$ and solvent casting

${ }^{47}$. The heat-casting method has less of an effect on bitumen's initial properties as it uses no solvent; therefore, we used it for sample preparation in this study ${ }^{48}$. To avoid a thin oxidized top layer, we always extracted bitumen samples $(1.5 \pm 0.5 \mathrm{mg})$ with a laboratory spatula at room temperature from a few centimeters below the surface of a bitumen bucket and spread it on a microscope coverslip. This created a thin bitumen film that covers an area of $\sim 4 \mathrm{~mm}^{2}$ with $500 \mu \mathrm{m}$ thickness (see Figure S1a and related supplementary information (SI) section for calculation details). We then covered the bitumen samples with a Petri dish and annealed them on a hot plate $\left(110^{\circ} \mathrm{C}\right)$ for five minutes. Then, we transferred the samples to a refrigerator $\left(3 \pm 2{ }^{\circ} \mathrm{C}\right)$ for $5 \mathrm{~min}$ to quench them to room temperature. We chose this time and temperature to minimize high-temperature aging and to ensure a sufficiently smooth sample surface for subsequent AFM scans ${ }^{44,45,49}$. Thermal history plays a significant role in the molecular reorganization of bitumen components ${ }^{25}$; therefore, following the above protocol was important in order to obtain consistent results. AFM scans were conducted on the prepared samples a few hours after preparation.

\section{Bulk chemistry characterization}

We characterized the chemistry of bitumen with the ATR-FTIR (Attenuated Total Reflectance Fourier Transform Infrared Spectroscopy) method using a Bruker Tensor 27 system (wavenumber range: 600 $\mathrm{cm}^{-1}$ to $3600 \mathrm{~cm}^{-1}$; resolution: $4 \mathrm{~cm}^{-1}$ ). Each final spectrum represents an accumulation of 32 individual spectra of the bulk material. First, the diamond detector surface of the FTIR device was cleaned with acetone. Then, a small quantity of bitumen was applied on the detector crystal at room temperature covering an area of $\sim 2 \mathrm{~mm}^{2}$. Before running the measurement, the lid of the FTIR device was closed, squeezing the bitumen on the diamond detector to create a thin uniform film.

\section{AFM-IR Characterization}

The AFM-IR technique can measure absorption spectra locally and can be used to chemically characterize a material with nanometer resolution in addition to the standard capabilities of an AFM. Both IR mapping and nanoscale IR spectra were carried out with a nanoIR2 device from Anasys Inc./Brucker at a suitable IR range of $892 \mathrm{~cm}^{-1}$ to $1958 \mathrm{~cm}^{-1}$ wavenumbers for characterizing organic materials such as bitumen.

Figure 1 presents an overview of the AFM-IR technique used in this study. It demonstrates chemical characterization measurements of the bitumen surface microstructures. Figure 1a shows an example of an AFM phase scan of bitumen at $-20^{\circ} \mathrm{C}$ (false-colored), revealing several microstructural domains. The bee-like striped area (yellow line indicates its boundary in Figure 1a) is the catana (wrinkled) domain, surrounded by the peri domain. The false-colored green area is the transition domain, and the blue area is the para domain. The red highlighted areas within the para domain are the sal subdomains. The sal sub-domain and transition domain emerge exclusively as a result of cooling to cold temperatures.

Figure $1 \mathrm{~b}$ shows a schematic indicating the position of the bitumen sample in the enclosed chamber while performing AFM-IR scans under controlled humidity and temperature conditions. We used aluminum and copper disks to elevate the sample position for the AFM-IR measurements. The environmental chamber position is under the AFM head to make an enclosed space for cantilever probe and sample to run AFM-IR scans in controlled conditions. A thermoelectric, water-cooled device under the sample holder controls the sample stage temperature. The circulating water temperature never goes below its freezing temperature, and to prevent condensation and frost on 
the sample surface, all AFM scans were performed under continuous Nitrogen flow resulting in a dry environment $(\mathrm{RH}<3 \%, \mathrm{~T} 3=20 \pm 3 \mathrm{\circ} \mathrm{C})$. Since we cannot monitor the surface temperature (T2) during scanning, we calibrated the sample surface temperature (T2) versus the stage temperature (T1) using a T-type thermocouple for similar conditions. Stage temperature $\mathrm{T} 1$ goes to $-35^{\circ} \mathrm{C}, \mathrm{T} 3$ (which measures the Nitrogen gas temperature) remains close to room temperature since we are continuously flooding the chamber with N2 at room temperature. Moreover, the AFM tip is oscillated at a resonance frequency, in tapping mode, and intermittently contacts the surface. Therefore we do not expect cantilever properties to change due to temperature.

The sample was cooled stepwise from room temperature $\left(\mathrm{T} 1: 25^{\circ} \mathrm{C}, 15^{\circ} \mathrm{C}, 0{ }^{\circ} \mathrm{C},-10^{\circ} \mathrm{C},-20^{\circ} \mathrm{C},-25^{\circ} \mathrm{C}\right.$, $-30{ }^{\circ} \mathrm{C}$, and $\left.-35^{\circ} \mathrm{C}\right)$. We cooled the stage with a high cooling rate $\left(\sim-90^{\circ} \mathrm{C} / \mathrm{min}\right)$, to reach the next temperature of the stepwise cooling cascade and then held that temperature constant for a minimum of 15 minutes (extra time might be needed for cantilever tuning) before performing the scan. After scanning at $\mathrm{T} 1=-35^{\circ} \mathrm{C}$, we heated the sample in two stage temperature (T1) steps: $0{ }^{\circ} \mathrm{C}$ and $25{ }^{\circ} \mathrm{C}$, to complete the temperature cycle and recover the samples to the initial conditions. For further investigating the cooling rate effect, we examined slow $(\sim-1.5 \stackrel{\circ}{\circ} / \mathrm{min})$ and fast $(\sim-90$ $\mathrm{o} / \mathrm{min}$ ) cooling rates for continuous cooling within a large temperature range, from $\mathrm{T} 1=25 \stackrel{ }{\circ} \mathrm{C}$ to

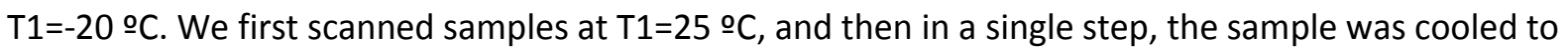

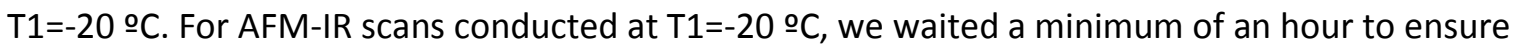
that the observed effect is only due to cooling.

Bitumen is a soft, sticky material; therefore, to prevent cantilever tip contamination, we used AFM-IR in tapping mode as is commonly done for bitumen ${ }^{45}$. The tapping cantilever (Figure 1c) follows the surface and generates the topography scan. The AFM phase scan contrast is generated by the differences between the oscillation phase of the driving signal sent to the AFM cantilever in tapping mode and its measured real mechanical oscillation response from the reflected laser ${ }^{3,50}$ (Figure 1d). It contains information on varying elasticity, friction, adhesion, viscosity, surface electrical charges, or chemical polarity. This measurement can provide qualitative information about how such properties vary over a surface. In particular, this is very relevant for bitumen imaged at different temperatures as its behavior can vary between elastic and viscous depending on the temperature. If more than one of these properties varies over a surface, then the phase image will measure the combination of the different contributions. Due to the fact that there is a combination of effects that give rise to the contrast in a phase image, it is not easy to attribute the contrast to one material property. Therefore, we alternatively use terms of "stiff" and "compliant" to represent any of these material properties, and we refer to the AFM phase image, "phase map" such as Figure $1 \mathrm{~d}$.

We conducted all scans in an enclosed environmental chamber at the scan rate of $0.7 \mathrm{~Hz}$ for a scan area of $15 \mu \mathrm{m}$ by $15 \mu \mathrm{m}$ with the resolution of 500 scan points and 250 scan lines. During the conditioning time before each scan, the AFM cantilever was set back to its free oscillation distance $(100 \mu \mathrm{m})$ to prevent tip contamination as bitumen has high volumetric variation during cooling and heating. Each AFM scan takes $\sim 5 \mathrm{~min}$. For each of the reheating steps, we quickly raised the sample temperature to reach the target temperature, and then, after about 30 min of the conditioning time, we performed an AFM scan with the same scan setting.

This article is protected by copyright. All rights reserved. 
The schematic drawing in Figure 1e shows that the absorbed IR pulse by the sample during the AFMIR scan causes a photothermal expansion. This results in an external impulse force, which causes an increase in amplitude at an alternate second oscillation mode of the cantilever. These two mechanical resonance modes occur simultaneously when the pulse frequency rate of the blinking IR laser, at a favorable IR absorption wavenumber for the sample material, is approximately equal to the frequency difference of the cantilever second and first mechanical resonances.

These data are used to map the surface chemistry (IR mapping and local IR spectra). IR maps are generated by the response intensity of each scan point of the material to the absorbed IR wavenumber. The absorption units, in volts, show the amplitude deflection of the cantilever in its second mechanical resonance mode, due to the local thermal expansion of the substrate material after reacting to the blinking IR laser beam. The absorption units are not quantitatively calibrated according to the concentration of each chemical functional group. Qualitatively, the more responding materials to the selected absorbed IR wavenumber show relatively higher absorption units in volts. ${ }^{33}$ In order to highlight the inhomogeneity of the material and domains, we plotted the offset value of the IR map contrast. The offset function sets the average IR absorption units equal to zero, and therefore, the initial intensities below average become negative.

The acquired AFM-IR spectra have high spatial resolution due to the fact that the cantilever probe has a sharp tip ( $~ 10 \mathrm{~nm}$ diameter) and high spectral resolution because of the sensitive laser feedback loop, which is able to detect fine cantilever deflections. When the bitumen surface absorbs a laser pulse, it expands deflecting the cantilever tip. The cantilever oscillation amplitude is proportional to the absorbed energy in sample ${ }^{35}$. The cantilever oscillation peaks are collected for different IR laser wavelengths, Fourier-transformed, and plotted as amplitude versus wavenumber. Nanoscale IR spectra show characteristic peaks at specific wavenumbers, which are used to define chemical functional groups.

\section{Image analysis: area fraction calculation}

Traditionally, the contrast in the AFM phase images is used to define qualitatively the borders separating the para and peri domains. Several device and set up specific effective parameters can be identified for the thresholding value defining the border, such as a difference in mechanical properties of each cantilever, energy, and force (set point) of the tapping cantilever; and substrate surface mechanical compliance as a function of temperature effects. As these parameters are setup-specific, it is not possible to report a single value for the phase scan to threshold the boundary of domains. Moreover, the existence of a high phase contrast in the catana (bee) domains disturbs the automatic thresholding procedure of the other domains. Therefore, the values reported here are selected to be specific to the experiments performed.

The phase contrast fades, and its sensitivity decreases at the colder temperatures because the stiffness of the tip-sample contact gets closer to the cantilever's stiffness. Darker colors in the phase map indicate phase lag between the driving and response frequencies. This occurs mainly in the relatively compliant parts of the sample. However, it is not feasible to convert phase map information to quantitate mechanical properties. For qualitative purposes, approximately the boundary of peri and para domains shows values in the range of zero to 0.5 degrees, which is the boundary of the relative stiff peri domain and compliant para domain while phase degrees of $0.5 \mathrm{deg}$ or larger indicating a substantial change in stiffness. 
Based on the AFM phase map analysis, we measured the surface area fraction for each of the domains. Even though half a degree of contrast in the phase image is sufficient to define peri and para domain boundaries, we measured the maximum contrast between these two peri and para domains to be $30-40^{\circ}$ degrees. However, from the AFM phase contrast (an example shown in Figure 2e and g), the para domain always has negative values (phase lag), but peri domain has heterogeneous phase value (shown as a non-uniform color contrast in visualized image). Sal sub-domain and transition domain also have heterogeneous phase makeup but close to para domain phase contrast. We recorded AFM in trace (forward) scans. These are left to right scans in the standard AFM scan configuration. Therefore, the narrow shadow at the boundary of transition and para domains, as well as the sal subdomain and para domain, is darker than both domains at the left-hand side and brighter at the righthand side (Figure $2 \mathrm{f}$ and $\mathrm{h}$ ). This narrow shadow between domains helps to define the boundaries of transition domain and sal sub-domain from the para and peri domains. The darker boundary around the para domain that emerges at cold temperatures we term as the transition domain (Figure $2 \mathrm{f}$ and $\mathrm{h}$ ), and we identified the round dark islands in the para domain as the sal sub-domain. False colored para, peri, and transition domains and calculated the area fraction of each domain (A sequence of results for domain identification is shown in Figure S3).

Sources of error include AFM scan resolution, tip sharpness, and operator error during postprocessing that are inevitable. To determine the error of the area fraction measurements, we ran 6 trials to calculate the area fraction for each domain for one randomly selected case (see example in Figure $4 \mathrm{~d}$, sample shown with the filled square symbol (-) at stage temperature $\mathrm{T} 1=-20^{\circ} \mathrm{C}$ ). For small area fractions, such as those found for the sal-sub domain, the area fraction errors can be as high as $27 \%$, but this value is less than $10 \%$ and $3 \%$ for the transition and para domains, respectively.

\section{IR spectra analysis}

Bitumen is a chemically complex mixture that has more than a thousand different types of molecule ${ }^{19}$. Its IR spectra have peaks corresponding to certain chemical functional groups. To determine IR indexes for such chemical groups around IR peaks. We chose a straight baseline for each peak passing through the intersection of each spectrum with the liming vertical lines around each peak. The selected range around each peak and the availability of the chemical functional groups for the bitumen SARA fractions are reported in Table 1.

\section{Results and discussion}

The wax content of bitumen plays a pivotal role in its low-temperature properties ${ }^{51}$. The investigated bitumen has a natural wax content of $1 \%$, as mentioned above. When bitumen is cooled from an annealing temperature, in this case, $110^{\circ} \mathrm{C}$, certain nano and micro-structures and domains emerge on the surface of heat casted samples in most bitumen types. The catana (bee) structures mentioned earlier, for example, are attributed to a waxy surface film ${ }^{4}$ as they disappear when the sample is heated above the melting point of waxes at ca $60^{\circ} \mathrm{C}^{45}$, (Figure 2a). Furthermore, they are indicators of the surface waxy layer mechanical mismatching with the bulk bitumen ${ }^{4}$.

The glass transition of the material reflects its bulk properties when the material undergoes during cooling a change from a viscous fluid to a glassy state ${ }^{52}$. In the case of bitumen, once the sample is further cooled to the region of its glass transition temperature (in this case ca $-20^{\circ} \mathrm{C}^{45}$ ), there is a further evolution of these micro and nanostructures. As bitumen is a composite material, different components tend to phase-change at different temperatures. This is reflected in Figure 2a and Figure

This article is protected by copyright. All rights reserved. 
$2 \mathrm{~b}$ that show AFM topography images of bitumen for the same location at $\mathrm{T} 1=25^{\circ} \mathrm{C}$ and $\mathrm{T} 1=-20^{\circ} \mathrm{C}$, respectively, selected as an example from the sequential stepwise stage temperature cooling. Figure $2 \mathrm{c}$ and Figure $2 \mathrm{~d}$ show magnified regions of Figure $2 \mathrm{a}$ and $\mathrm{b}$, respectively. Figure $2 \mathrm{e}$ and Figure $2 \mathrm{f}$ are AFM phase images (phase map) for the same location at $\mathrm{T} 1=25{ }^{\circ} \mathrm{C}$ and $\mathrm{T} 1=-20{ }^{\circ} \mathrm{C}$, respectively, where positive and negative values indicate relative higher and lower material stiffness, respectively. Figure $2 \mathrm{~g}$ and Figure $2 \mathrm{~h}$ are magnified regions of Figure $2 \mathrm{e}$ and Figure $2 \mathrm{f}$, respectively.

The phase images, reflecting the sample interaction with the tip of AFM, corroborate what has been reported in literature ${ }^{3}$ and shows at both temperatures there is a distinct difference between para and peri domains indicating the relative stiffness and adhesion of the domains increasing from para to peri. The softer part of the material has a more substantial interaction with the AFM tip resulting in the darker image. The peri domain is hard and rough, and its surface coarsens at colder temperatures. In contrast, the para domain is relatively soft and based on the corresponding topography scan, it is also smooth. Figure $2 \mathrm{~h}$ shows that with cooling, there is less contrast between the domains as they reach their glassy state, and furthermore, two main evolutions of the surface microstructure take place. The first in the para domain, where we see the appearance of protruding islands, the so-called sal subdomains ${ }^{13}$ and second in the peri domain the formation of an interfacial "transition" region at colder temperatures.

Previous studies have shown that different SARA fractions of bitumen have different glass transition temperatures (Tgs) that are affected by their composition, ranging from $-88^{\circ} \mathrm{C}$ to $60^{\circ} \mathrm{C}$, increasing from low molecular weight saturates to high molecular weight asphaltenes ${ }^{13}$. This has the consequence that different microstructures appear at different temperatures. In addition, similar studies have shown that the sal sub-domain contains the lowest molecular weight amorphous alkane of the para domain and remains amorphous, not crystallizing at deeply subfreezing temperatures ${ }^{13}$. We also see that with cooling, the para domain stiffens relative to the peri and catana domains, but the transition domain and sal sub-domain remain noticeability soft relative to the peri and catana domains (see Supporting Information, Figure S3, and Figure S4). During stepwise cooling, the sal sub-domain can grow to about $1 \mu \mathrm{m}$ diameter. The transition domain has $0.5 \pm 0.1 \mu \mathrm{m}$ rather uniform width with some locations, such as sharp corners featuring a higher width of 1-2 $\mu \mathrm{m}$. For a high cooling rate of $\sim-90^{\circ} \mathrm{C} / \mathrm{min}$, an individual sal sub-domain equivalent diameter is limited to $\sim 100 \mathrm{~nm}$ beads, while the transition domain is narrower and has a width of a couple of hundred nanometers. In the case of a slow cooling rate, $\sim-1.5^{\circ} \mathrm{C} / \mathrm{min}$, it is difficult to detect the sal sub-domain, and the boundary of the para and peri domains features a diffuse transition domain.

Figure $3 \mathrm{a}$ and $\mathrm{b}$ show representative bitumen AFM topography scans at two different temperatures, $\mathrm{T} 1=25^{\circ} \mathrm{C}$ and $\mathrm{T} 1=-20^{\circ} \mathrm{C}$, respectively. Also shown are the paths traveled by the AFM tip along the surface, crossing a catana structure, and the emerging transition domain defined earlier. These paths are chosen at practically the same location of the same sample and produce the topography landscapes of Figure $3 \mathrm{c}$, showing the effect of reducing the temperature from $\mathrm{T} 1=25^{\circ} \mathrm{C}$ to $\mathrm{T} 1=-20^{\circ} \mathrm{C}$ on the microstructural. It can be seen that a typical catana domain has a length of $4 \pm 3 \mu \mathrm{m}$ and a maximum amplitude of $100 \pm 50 \mathrm{~nm}$. Cooling causes the material to shrink, and therefore the distance between surface microstructures changes and the bee structures to shift (marked with a circle) at cold temperatures in comparison to their original location at room temperature. It is clear that cooling affects the surface texture of bitumen in all areas and in particular, the emerging sal sub-domains and transition domains (see Figure S5 where domains are defined on the topography plot based on the corresponding phase scans). After cooling, the amplitude and length of the bee structure decreased by $10-20 \%$ while the wavelength varied around its initial value, Figure 3c. (For more details see Figure

This article is protected by copyright. All rights reserved. 
$\mathrm{S} 7$ in the SI document). The profile also shows the drift of the microstructures as a result of the cooling. One possible explanation for the appearance of the sal domains was discussed by Masson et al. ${ }^{13}$ (Masson 2007) is that the sal sub-domain and the transition domain have less volumetric changes than that of their surroundings, due to the fact that they have a different composition and as a result different Tgs.

Bitumen is highly temperature-sensitive, the evolution of the microstructures is further demonstrated in Figure $4 \mathrm{a}, \mathrm{b}$ and $\mathrm{c}$, which are examples of AFM phase images of the stepwise temperature cycles starting at $\mathrm{T} 1=25^{\circ} \mathrm{C}$, cooling down to $\mathrm{T} 1=-35^{\circ} \mathrm{C}$ and reheating to $\mathrm{T} 1=25^{\circ} \mathrm{C}$. We conducted each sequence of scans at practically the same location and repeated the scans at the same conditions on three fresh samples. Considering the formation of new domains at colder temperatures, the impact of the cooling on the area fraction of these domains was further studied. Figure $4 \mathrm{~d}$ shows the area fractions of the sal sub-domain (red), transition domain (green), and para (blue) domain, at the bitumen surface and T1 and T2 vs. time. In addition to T1, the temperature cycles were measured at the surface of the bitumen (T2) and shown (recall the locations of the thermocouples for T1 and T2 in Figure 1b). The temperature history for $\mathrm{T} 1$ and $\mathrm{T} 2$ measurements are depicted by dashed and straight black lines, respectively. A comparison of the surface temperature T2 with the stage temperature T1 indicates that thermal lag within the sample is negligible, and the selected conditioning time for each step is sufficient to reach thermal equilibrium (see Figure S1 in SI for thermal resistance calculation).

We see that the para area fraction decreases with decreasing temperature while the transition and sal area fractions increase with decreasing temperature. Initially, the para domain area fraction decreases while, simultaneously, the new transition domain and sal sub-domain emerge. Accordingly, the area fractions of the sal sub-domain and transition domain increase and eventually plateau (see a sequence of the image analysis, Figure S3). As mentioned earlier, the sal sub-domains contain the lowest molecular weight amorphous alkanes within the para domain, which precipitate and protrude from the surface between $-10{ }^{\circ} \mathrm{C}$ and $-19^{\circ} \mathrm{C}{ }^{13}$. The width of the affected area around the protruded zone is about 2-4 $\mu \mathrm{m}$ and the height of about $20 \mathrm{~nm}$.

Figure 5a, b, and c show topography, phase, and chemical IR mapping (at wavenumber $1456 \mathrm{~cm}^{-1}$; main $\mathrm{H}-\mathrm{C}$ peak of bitumen) of the sample at $\mathrm{T} 1=25^{\circ} \mathrm{C}$, respectively. Figure $5 \mathrm{~d}$, e, and $\mathrm{f}$ show the same information at practically the same location, but for $\mathrm{T} 1=-20^{\circ} \mathrm{C}$, after cooling at a relatively slow cooling rate $\left(\sim-1.5^{\circ} \mathrm{C} / \mathrm{min}\right)$ directly from $\mathrm{T} 1=25^{\circ} \mathrm{C}$ to $\left.\mathrm{T} 1=-20^{\circ} \mathrm{C}\right)$. Figure $5 \mathrm{~g}$ shows the absorbance spectrum vs. wave number for bulk FTIR $\left(\sim 23^{\circ} \mathrm{C}\right)$; local nanoscale IR spectra of the peri and para domains at $\mathrm{T} 1=25^{\circ} \mathrm{C}$; and the peri, para, and transition domains at $\mathrm{T} 1=-20^{\circ} \mathrm{C}$. The locations where local nanoscale IR spectroscopies were performed are shown with squares in Figure $5 \mathrm{~b}$ and e.

Previous studies showed that the IR spectra of the SARA fractions have high similarity ${ }^{21}$, but their concentrations are different at the bitumen surface microstructures ${ }^{13}$. The straight vertical line (Figure $5 \mathrm{~g}$ ) shows the location of the $1456 \mathrm{~cm}^{-1}$ wavenumber on the IR spectra. The peri domain is already a crystalized domain at $25^{\circ} \mathrm{C}$, as it has a higher percentage of paraffinic and saturated compounds ${ }^{32}$. The peri domain shows a clear contrast with the para domain at $25^{\circ} \mathrm{C}$. On the other hand, at colder temperatures, the para domain becomes as stiffer as the peri domain and sal sub-domains, which consist of the light molecules of the para domain ${ }^{13}$. Stiffer para with the denser molecular arrangement at $-20{ }^{\circ} \mathrm{C}$ and sal-sub domain makeup result in an increase of the IR signal intensity and noisier IR map of the surface domains at $-20^{\circ} \mathrm{C}$ (Figure 5e) compared to $25^{\circ} \mathrm{C}$ (Figure 5b). The IR peak is broader around $1456 \mathrm{~cm}^{-1}$ wavenumber for the IR spectra of peri and para domains at $25^{\circ} \mathrm{C}$ and the transition domain at $-20^{\circ} \mathrm{C}$ compared to peri and para domains at $-20^{\circ} \mathrm{C}$. 
AFM-IR is a mechanical technique; thus, the tapping IR spectra have inherent noise signals. To facilitate the distinction of the trends, we smoothened the AFM-IR spectra by the Savitzy-Golay function using a polynomial order of five, fitting six neighboring points (original spectra is reported in Figure S9). Bitumen has reference characteristic IR absorption spectra peaks (1376 and $1456 \mathrm{~cm}^{-1}$ ) corresponding to the bending vibration of $\mathrm{CH}_{2}$ and $\mathrm{CH}_{3}$ aliphatic hydrocarbons ${ }^{53,54}$. Owing to the bitumen composition as a mixture of various hydrocarbons, these are present in all types of bitumen ${ }^{54}$. These peaks are also strongly present in both the bulk bitumen FTIR signal (black line at Figure $5 \mathrm{~g}$ ), and the local nanoscale IR spectra from the different domains probed. Therefore, the wave number $1456 \mathrm{~cm}^{-1}$ was selected for the IR mapping. The results show that the peri domain has a distinct chemical signature compared to the para domain (Figure $5 \mathrm{c}$ ). In cold bitumen, however (Figure $5 \mathrm{e}$ and $\mathrm{f}$, at $\mathrm{T} 1=-20^{\circ} \mathrm{C}$ ) the boundary of the peri domain is chemically and mechanically practically indistinguishable from the para domain. At $\mathrm{T} 1=25^{\circ} \mathrm{C}$, although the nanoscale IR spectra of para and peri domains follow the bulk FTIR signal, there are also significant deviations around wavenumbers $958-1049 \mathrm{~cm}^{-1}$ and $1353-1394 \mathrm{~cm}^{-1}$ and later from 1546 to $1626 \mathrm{~cm}^{-1}$ and 1690 to 1710 $\mathrm{cm}^{-1}$ (Figure $5 \mathrm{~g}$ ). As a consequence of cooling, the nanoscale IR spectra intensity of the para domain at $\mathrm{T} 1=-20^{\circ} \mathrm{C}$ shifts upward around wavenumbers $958-1049 \mathrm{~cm}^{-1}$ (Figure $5 \mathrm{~g}$ ). IR peak values of 1030 $\mathrm{cm}^{-1}$ are attributed to the sulfoxide functional group ${ }^{28}$ which are present in resins and asphaltene fractions ${ }^{21}$.

In order to quantify the intensity of the major peaks in Figure $5 \mathrm{~g}$, we integrated the different areas, $A$, under the curve around a band maximum $\left(A_{\text {peak }}\right.$ shows area under each band maximum and above straight baseline crossing spectra at limiting wavenumbers). Based on previous studies ${ }^{28,55,56} \mathrm{We}$ defined the FTIR indexes and the limits of integration as follows: sulfoxide $\left(\mathrm{A}_{1030}: 958-1049 \mathrm{~cm}^{-1}\right)$, aliphatic $\left(A_{1376}: 1353-1394 \mathrm{~cm}^{-1}\right.$ and $\left.A_{1456}: 1407-1500 \mathrm{~cm}^{-1}\right)$, aromatic $\left(A_{1600}: 1546-1626 \mathrm{~cm}^{-1}\right)$, and carbonyl $\left(A_{1700}: 1690-1710 \mathrm{~cm}^{-1}\right)$ groups. The total area is defined as $\sum A=A_{1030}+A_{1376}+A_{1456}+$ $\mathrm{A}_{1600}+\mathrm{A}_{1700}$ for each spectra. By dividing the areas under the peaks by the total area $\sum \mathrm{A}$, we define an index for each absorbance band, in order to make comparisons possible. Indexes show the relative distribution of chemical functional groups for each spectrum. For some specific cases, the difference of various domains is within the error bars and, therefore, not significant. These results, as well as the availability of the chemical functional groups for each fraction of the SARA fractions ${ }^{21,57}$ are shown in Table 1 and Figure 6, respectively. As indicated, previous reports that used s-SNOM to characterize bitumen found a distinguishable chemical difference between the para and peri domains and showed that concentrations of sulfoxide and carbonyl groups are different in the peri and para domains ${ }^{32}$; however, the IR spectra of these domains are not reported. On the other hand, a recent study ${ }^{38}$ on bitumen using a similar AFM-IR device and sample preparation method show that the peri domain also contains sulfoxide groups.

In contrast to the bulk FTIR, Figure 6 shows that all the major bitumen bulk functional groups are present in the para, peri, and transition domains. However, the relative amount varies with domain and with temperature. Comparing the para and peri at $25^{\circ} \mathrm{C}$, it is apparent that the carbonyl functional groups are considerably lower at the peri domain. At $-20^{\circ} \mathrm{C}$, there is a shift in the functional groups with the branched alkanes $\left(1376 \mathrm{~cm}^{-1}\right)$ relatively lower value in para and higher in the peri domain. In addition, there is a considerable increase in the aromatics in the peri at $-20^{\circ} \mathrm{C}$. The transition appears at colder temperatures showing strong aliphatic peaks. At cold temperatures, the para domain surface functional groups change- $A_{1030}$ and $A_{1700}$ increased while $A_{1600}$ and $\left(A_{1376}+A_{1456}\right)$ decreased (aliphatic) - with the emergence of the sal sub-domain and transition domain. It is also clear that the spectrum of the transition domain lies between the peri and para domains. 
Figure 7a, b, c and d show topography, phase map, magnified phase map of the para domain, and chemical IR (at wavenumber $1456 \mathrm{~cm}^{-1}$ ) images of bitumen at $\mathrm{T} 1=25^{\circ} \mathrm{C}$, respectively. Figure $7 \mathrm{e}, \mathrm{f}, \mathrm{g}$, and $\mathrm{h}$ show the same results at practically the same location, but now at $\mathrm{T} 1=-20^{\circ} \mathrm{C}$, after a fast temperature reduction directly from $\mathrm{T} 1=25^{\circ} \mathrm{C}$ to $\mathrm{T} 1=-20^{\circ} \mathrm{C}$ with cooling rate of $\sim-90{ }^{\circ} \mathrm{C} / \mathrm{min}$ (i.e., continuous cooling from $\mathrm{T} 1=25^{\circ} \mathrm{C}$ to $\mathrm{T} 1=-20^{\circ} \mathrm{C}$ in half a minute). This cooling rate that can have a direct effect on the $\mathrm{Tg}$, as discussed in the SI, is limited by the fastest cooling rate capacity of the water-cooled thermoelectric device of the environmental chamber. By comparing the magnified panels of Figure 7 (Figure 7c and g), we observe that upon cooling, the para domain coarsens through the nucleation of the sal sub-domain. Hence, a narrow transition domain develops between peri and para domains after a fast cooling rate of $-90{ }^{\circ} \mathrm{C} / \mathrm{min}$.

On the other hand, a slow cooling rate of $-1.5^{\circ} \mathrm{C} / \mathrm{min}$ does not allow the development of a sizable sal sub-domain at the para domain (Figure 5e). In contrast to the fast cooling rate (shown in Figure 7), there is a reduced contrast between para and peri domains in a comparable slow cooling rate of -1.5 ${ }^{\circ} \mathrm{C} / \mathrm{min}$ (Figure 5) due to the fact that the material does not have sufficient time for the development of a sizable transition domain between the para and peri domains. Moreover, a sharp narrow transition domain develops between peri and para domains, and numerous evenly spread sal subdomains emerge in the para domain after experiencing a fast cooling rate of $-90^{\circ} \mathrm{C} / \mathrm{min}$. It is shown that the cooling procedure affects the distribution of the sal sub-domain as well as the size of the interfacial zone; this is a function of temperature, sal nucleation, and transport phenomena.

\section{Conclusion}

Employing advanced AFM-IR imaging, we showed that cooling bitumen to sub-zero environmental conditions causes significant changes in its mechanical, chemical, and topographical surface properties. We also found that new surface domains emerge at cold environmental conditions, namely, the transition domain between peri and para domains and the sal sub-domain, consisting of distinct island regions within the para domain. Nanoscale infrared spectroscopy showed that the transition domain has a chemical composition that is intermediate between those of the para and peri domains. We also showed that the peri and para domains are mechanically and chemically distinct at ambient conditions; however, when cooled to sub-zero conditions, phase imaging and nanoscale infrared spectroscopy indicate that the properties in sample domains appear to become similar and that the transition domain-which separates them-emerges and broadens. This can be expected on the one hand as the different domains go through their respective glass transition and display stiffer properties. however, when cooled to sub-zero conditions, phase imaging and nanoscale infrared spectroscopy reveal that their properties become similar and that the transition domainwhich separates them - emerges and broadens. And on the other hand, the diminishing of phase contrast is also a result of the sample becoming stiffer with cold temperatures - and therefore the contact stiffness becoming larger, which means that the tip doesn't penetrate the sample as much and thus the phase is less sensitive to material properties and therefore the contrast goes down in the phase images so that the AFM derived stiffness of different areas on the sample appear to be similar. Their emergence and distribution are highly dependent on how the sample is cooled, and the initial para domain size and shape. Also, very rapid, constant cooling rates over significant temperature differences, hinder the migration of sal sub-domains from forming large transition domains. Concerning chemical composition, we showed that the catana domain has the same chemistry as the surrounding peri domain. The amplitude of the catana structures decreases as a

This article is protected by copyright. All rights reserved. 
function of cooling, but the wavelength remains practically about the initial value. The results of this work significantly improve our fundamental understanding of the behavior of bitumen at sub-zero environmental temperatures, which, in addition to its fundamental value, has implications for the performance of bitumen in applications ranging from sealing to road engineering.

\section{Acknowledgments}

Financial support of the Swiss National Science Foundation under grant number 200020_169122 / 1 and the European Research Council under Advanced Grant 669908 (INTICE) are acknowledged. Beatrice Fischer of Empa is acknowledged for performing the FTIR measurements. Technical support from Bruker, specifically from Anirban Roy, Miriam Unger, and Igor Arkov, is gratefully acknowledged.

\section{References}

(1) Read, J.; Whiteoak, D. The Shell Bitumen Handbook. Read, J., \& Whiteoak, D. (2003). The Shell bitumen handbook. Thomas Telford. 2003, p 29. https://doi.org/10.1680/sbh.32200.

(2) Loeber, L.; Muller, G.; Morel, J.; Sutton, O. Bitumen in Colloid Science: A Chemical, Structural and Rheological Approach. Fuel 1998, 77 (13), 1443-1450. https://doi.org/10.1016/S00162361(98)00054-4.

(3) MASSON, J.-F.; LEBLOND, V.; MARGESON, J. Bitumen Morphologies by Phase-Detection Atomic Force Microscopy. J. Microsc. 2006, 221 (1), 17-29. https://doi.org/10.1111/j.13652818.2006.01540.x.

(4) Hung, A. M.; Fini, E. H. AFM Study of Asphalt Binder "Bee" Structures: Origin, Mechanical Fracture, Topological Evolution, and Experimental Artifacts. RSC Adv. 2015, 5 (117), 9697296982. https://doi.org/10.1039/C5RA13982A.

(5) Hofko, B.; Maschauer, D.; Steiner, D.; Grothe, H.; Mirwald, J. Chemical Composition and Microstructure of Bitumen - a Matter of Terminology?; Springer, Cham, 2019; pp 145-149. https://doi.org/10.1007/978-3-030-00476-7_23.

(6) Lu, X.; Langton, M.; Olofsson, P.; Redelius, P. Wax Morphology in Bitumen. J. Mater. Sci. 2005, 40 (8), 1893-1900. https://doi.org/10.1007/s10853-005-1208-4.

(7) Kané, M.; Djabourov, M.; Volle, J. L.; Lechaire, J. P.; Frebourg, G. Morphology of Paraffin Crystals in Waxy Crude Oils Cooled in Quiescent Conditions and under Flow. Fuel 2003, 82 (2), 127-135. https://doi.org/10.1016/S0016-2361(02)00222-3.

(8) Zbik, M.; Horn, R. G.; Shaw, N. AFM Study of Paraffin Wax Surfaces. Colloids Surfaces A Physicochem. Eng. Asp. 2006, 287 (1-3), 139-146. https://doi.org/10.1016/j.colsurfa.2006.03.043.

(9) Isacsson, U.; Zeng, H. Relationships between Bitumen Chemistry and Low Temperature Behaviour of Asphalt. Constr. Build. Mater. 1997, 11 (2), 83-91. https://doi.org/10.1016/S0950-0618(97)00008-1.

(10) Cavalli, M. C.; Zaumanis, M.; Mazza, E.; Partl, M. N.; Poulikakos, L. D. Effect of Ageing on the Mechanical and Chemical Properties of Binder from RAP Treated with Bio-Based

This article is protected by copyright. All rights reserved. 
Rejuvenators. Compos. Part B Eng. 2018, 141 (May), 174-181.

https://doi.org/10.1016/j.compositesb.2017.12.060.

(11) Petersen, J. C. A Review of the Fundamentals of Asphalt Oxidation (E-C140). Transp. Res. Rec. J. Transp. Res. Board 2009, E-C140 (October), 1-78. https://doi.org/10.17226/23002.

(12) Das, P. K.; Kringos, N.; Birgisson, B. Microscale Investigation of Thin Film Surface Ageing of Bitumen. J. Microsc. 2014, 254 (2), 95-107. https://doi.org/10.1111/jmi.12122.

(13) Masson, J. F.; Leblond, V.; Margeson, J.; Bundalo-Perc, S. Low-Temperature Bitumen Stiffness and Viscous Paraffinic Nano- and Micro-Domains by Cryogenic AFM and PDM. J. Microsc. 2007, 227 (3), 191-202. https://doi.org/10.1111/j.1365-2818.2007.01796.x.

(14) Mercé, M.; Saadaoui, H.; Dole, F.; Buisson, L.; Bentaleb, A.; Ruggi, D.; Schmitt, V.; Backov, R. Importance of Thermal Gradient in the Bitumen Bees Genesis. J. Mater. Sci. 2015. https://doi.org/10.1007/s10853-015-9202-y.

(15) Nahar, S.; Mohajeri, M.; Schmets, A.; Scarpas, A.; van de Ven, M.; Schitter, G. First Observation of Blending-Zone Morphology at Interface of Reclaimed Asphalt Binder and Virgin Bitumen. Transp. Res. Rec. J. Transp. Res. Board 2013, 2370 (December), 1-9. https://doi.org/10.3141/2370-01.

(16) Schmets, A.; Kringos, N.; Pauli, T.; Redelius, P.; Scarpas, T. On the Existence of Wax-Induced Phase Separation in Bitumen. Int. J. Pavement Eng. 2010, 11 (6), 555-563. https://doi.org/10.1080/10298436.2010.488730.

(17) Lyne, Å. L.; Wallqvist, V.; Rutland, M. W.; Claesson, P.; Birgisson, B. Surface Wrinkling: The Phenomenon Causing Bees in Bitumen. J. Mater. Sci. 2013, 48 (20), 6970-6976. https://doi.org/10.1007/s10853-013-7505-4.

(18) Pauli, A. T.; Grimes, R. W.; Beemer, A. G.; Turner, T. F.; Branthaver, J. F. Morphology of Asphalts, Asphalt Fractions and Model Wax-Doped Asphalts Studied by Atomic Force Microscopy. Int. J. Pavement Eng. 2011, 12 (4), 291-309. https://doi.org/10.1080/10298436.2011.575942.

(19) Lesueur, D. The Colloidal Structure of Bitumen: Consequences on the Rheology and on the Mechanisms of Bitumen Modification. Adv. Colloid Interface Sci. 2009, 145 (1-2), 42-82. https://doi.org/10.1016/j.cis.2008.08.011.

(20) Lesueur, D.; Gerard, J.; Claudy, P.; Letoffe, J.; Planche, J.; Martin, D. A Structure-related Model to Describe Asphalt Linear Viscoelasticity. J. Rheol. (N. Y. N. Y). 1996, 40 (5), 813-836. https://doi.org/10.1122/1.550764.

(21) Zhang, C.; Xu, T.; Shi, H.; Wang, L. Physicochemical and Pyrolysis Properties of SARA Fractions Separated from Asphalt Binder. J. Therm. Anal. Calorim. 2015, 122 (1), 241-249. https://doi.org/10.1007/s10973-015-4700-3.

(22) Speight, J. The Desulfurization of Heavy Oils and Residua; 1999. https://doi.org/10.1016/0378-3820(82)90041-8.

(23) Shi, H.; Xu, T.; Zhou, P.; Jiang, R. Combustion Properties of Saturates, Aromatics, Resins, and Asphaltenes in Asphalt Binder. Constr. Build. Mater. 2017, 136, 515-523.

https://doi.org/10.1016/j.conbuildmat.2017.01.064.

(24) Claudy, P.; Letoffe, J. M.; King, G. N.; Planche, J. P.; Brule, B. Characterization of Paving

This article is protected by copyright. All rights reserved. 
Asphalts by Differential Scanning Calorimetry. Fuel Sci. Technol. Int. 1991, 9 (1), 71-92. https://doi.org/10.1080/08843759108942254.

(25) Masson, J. F.; Polomark, G. M.; Collins, P. Time-Dependent Microstructure of Bitumen and Its Fractions by Modulated Differential Scanning Calorimetry. Energy and Fuels 2002, 16 (2), 470-476. https://doi.org/10.1021/ef010233r.

(26) Masson, J. F.; Polomark, G. M.; Bundalo-Perc, S.; Collins, P. Melting and Glass Transitions in Paraffinic and Naphthenic Oils. Thermochim. Acta 2006, 440 (2), 132-140. https://doi.org/10.1016/j.tca.2005.11.001.

(27) Masson, J.-F. F.; Polomark, G. . M. Bitumen Microstructure by Modulated Differential Scanning Calorimetry. Thermochim. Acta 2001, 374 (2), 105-114. https://doi.org/10.1016/S0040-6031(01)00478-6.

(28) Gong, M.; Yang, J.; Wei, J.; Pauli, T.; Yu, H. Quantitative Characterisation of Asphalt's Composition-Microstructure Relationship Based on Atomic Force Microscopy, Differential Scanning Calorimetry, and Fourier Transform Infrared Spectroscopy Tests. Road Mater. Pavement Des. 2017, 18 (3), 507-532. https://doi.org/10.1080/14680629.2016.1181560.

(29) Sjövall, P.; Pomerantz, A. E.; Lu, X.; Mullins, O. C. Time of Flight-Secondary Ion Mass Spectrometry (TOF-SIMS) Study of Diverse Asphaltenes. Fuel 2018, 220 (February), 638-644. https://doi.org/10.1016/j.fuel.2018.02.017.

(30) Lu, X.; Sjövall, P.; Soenen, H.; Andersson, M. Microstructures of Bitumen Observed by Environmental Scanning Electron Microscopy (ESEM) and Chemical Analysis Using Time-ofFlight Secondary Ion Mass Spectrometry (TOF-SIMS). Fuel 2018, 229, 198-208. https://doi.org/10.1016/J.FUEL.2018.05.036.

(31) Lu, X.; Sjövall, P.; Soenen, H. Structural and Chemical Analysis of Bitumen Using Time-of-Flight Secondary Ion Mass Spectrometry (TOF-SIMS). Fuel 2017, 199, 206-218. https://doi.org/10.1016/J.FUEL.2017.02.090.

(32) Fischer, H. R.; Cernescu, A. Relation of Chemical Composition to Asphalt Microstructure Details and Properties of Micro-Structures in Bitumen as Seen by Thermal and Friction Force Microscopy and by Scanning near-Filed Optical Microscopy. Fuel 2015, 153, 628-633. https://doi.org/10.1016/j.fuel.2015.03.043.

(33) Dazzi, A.; Prater, C. B. AFM-IR: Technology and Applications in Nanoscale Infrared Spectroscopy and Chemical Imaging. Chem. Rev. 2017, 117 (7), 5146-5173. https://doi.org/10.1021/acs.chemrev.6b00448.

(34) Centrone, A. Infrared Imaging and Spectroscopy Beyond the Diffraction Limit. Annu. Rev. Anal. Chem. 2015, 8 (1), 101-126. https://doi.org/10.1146/annurev-anchem-071114-040435.

(35) Dazzi, A.; Prazeres, R.; Glotin, F.; Ortega, J. M. Analysis of Nano-Chemical Mapping Performed by an AFM-Based ("AFMIR") Acousto-Optic Technique. Ultramicroscopy 2007, 107 (12), 11941200.

(36) Dazzi, A.; Prater, C. B.; Hu, Q.; Chase, D. B.; Rabolt, J. F.; Marcott, C. AFM - IR : Combining Atomic Force Microscopy and Infrared Spectroscopy for Nanoscale Chemical Characterization. Appl. Spectrosc. 2012, 66 N62, 1365-1384. https://doi.org/10.1366/1206804. 
(37) Dazzi, A.; Saunier, J.; Kjoller, K.; Yagoubi, N. Resonance Enhanced AFM-IR: A New Powerful Way to Characterize Blooming on Polymers Used in Medical Devices. Int. J. Pharm. 2015, 484 (1-2), 109-114. https://doi.org/10.1016/j.ijpharm.2015.02.046.

(38) Xing, C.; Liu, L.; Cui, Y.; Ding, D. Analysis of Base Bitumen Chemical Composition and Aging Behaviors via Atomic Force Microscopy-Based Infrared Spectroscopy. Fuel 2020, 264 (December 2019), 116845. https://doi.org/10.1016/j.fuel.2019.116845.

(39) De Moraes, M. B.; Pereira, R. B.; SimÃo, R. A.; Leite, L. F. M. High Temperature AFM Study of CAP 30/45 Pen Grade Bitumen. J. Microsc. 2010, 239 (1), 46-53.

https://doi.org/10.1111/j.1365-2818.2009.03354.x.

(40) Nahar, S. N.; Schmets, A. J. M.; Scarpas, A.; Schitter, G. Temperature and Thermal History Dependence of the Microstructure in Bituminous Materials. Eur. Polym. J. 2013, 49 (8), 19641974. https://doi.org/10.1016/j.eurpolymj.2013.03.027.

(41) Fischer, H. R.; Dillingh, E. C.; Hermse, C. G. M. On the Microstructure of Bituminous Binders. Road Mater. Pavement Des. 2014, 15 (1), 1-15. https://doi.org/10.1080/14680629.2013.837838.

(42) Das, P. K.; Kringos, N.; Wallqvist, V.; Birgisson, B. Micromechanical Investigation of Phase Separation in Bitumen by Combining Atomic Force Microscopy with Differential Scanning Calorimetry Results. Road Mater. Pavement Des. 2013, 14 (SUPPL.1), 25-37. https://doi.org/10.1080/14680629.2013.774744.

(43) Qin, Q.; Farrar, M. J.; Pauli, A. T.; Adams, J. J. Morphology, Thermal Analysis and Rheology of Sasobit Modified Warm Mix Asphalt Binders. Fuel 2014, 115, 416-425.

https://doi.org/10.1016/j.fuel.2013.07.033.

(44) Yu, X.; Burnham, N. A.; Tao, M. Surface Microstructure of Bitumen Characterized by Atomic Force Microscopy. Adv. Colloid Interface Sci. 2015, 218, 17-33. https://doi.org/10.1016/j.cis.2015.01.003.

(45) Soenen, H.; Besamusca, J.; Fischer, H. R.; Poulikakos, L. D.; Planche, J.-P.; Das, P. K.; Kringos, N.; Grenfell, J. R. A.; Lu, X.; Chailleux, E. Laboratory Investigation of Bitumen Based on Round Robin DSC and AFM Tests. Mater. Struct. 2014, 47 (7), 1205-1220.

https://doi.org/10.1617/s11527-013-0123-4.

(46) Loeber, L.; Sutton, O.; Morel, J. New Direct Observations of Asphalts and Asphalt Binders by Scanning Electron Microscopy and Atomic Force Microscopy. ... Microsc. 1996, 182 (April), 32-39.

(47) Biró, L. P. Atomic Force Microscopy Investigation of Carbon Nanotubes. In Carbon Filaments and Nanotubes: Common Origins, Differing Applications?; 2001; Vol. 46, pp 255-263. https://doi.org/10.1007/978-94-010-0777-1_18.

(48) Mccarron, B.; Yu, X.; Tao, M.; Burnham, N. The Investigation of 'Bee -Structures' in Asphalt Binders. 2012, 1-48.

(49) Fischer, H. R.; Dillingh, E. C. On the Investigation of the Bulk Microstructure of Bitumen Introducing Two New Techniques. Fuel 2014, 118 (1), 365-368.

https://doi.org/10.1016/j.fuel.2013.11.008 Short communication.

(50) Chakraborty, I.; Yablon, D. G. Cantilever Energy Effects on Bimodal AFM: Phase and 
Amplitude Contrast of Multicomponent Samples. Nanotechnology 2013, 24 (47).

https://doi.org/10.1088/0957-4484/24/47/475706.

(51) Das, P. K.; Jelagin, D.; Birgisson, B.; Kringos, N. Micro-Mechanical Investigation of Low Temperature Fatigue Cracking Behaviour of Bitumen. 7th RILEM Int. Conf. Crack. Pavements 2012, 4, 1281-1290. https://doi.org/10.1007/978-94-007-4566-7_122.

(52) ISO 11357-2: Plastics -- Differential Scanning Calorimetry (DSC) -- Part 2: Determination of Glass Transition Temperature; 1999.

(53) Hofko, B.; Porot, L.; Falchetto Cannone, A.; Poulikakos, L.; Huber, L.; Lu, X.; Mollenhauer, K.; Grothe, H. FTIR Spectral Analysis of Bituminous Binders: Reproducibility and Impact of Ageing Temperature. Mater. Struct. Constr. 2018, 51 (2). https://doi.org/10.1617/s11527-018-11707.

(54) Weigel, S.; Stephan, D. The Prediction of Bitumen Properties Based on FTIR and Multivariate Analysis Methods. Fuel 2017, 208, 655-661. https://doi.org/10.1016/j.fuel.2017.07.048.

(55) Lamontagne, J.; Dumas, P.; Mouillet, V.; Kister, J. Comparison by Fourier Transform Infrared (FTIR) Spectroscopy of Different Ageing Techniques: Application to Road Bitumens. Fuel 2001, 80 (4), 483-488. https://doi.org/10.1016/S0016-2361(00)00121-6.

(56) Permanyer, A.; Douifi, L.; Lahcini, A.; Lamontagne, J.; Kister, J. FTIR and SUVF Spectroscopy Applied to Reservoir Compartmentalization: A Comparative Study with Gas Chromatography Fingerprints Results. Fuel 2002, 81 (7), 861-866. https://doi.org/10.1016/S00162361(01)00211-3.

(57) Aguiar-Moya, J. P.; Salazar-Delgado, J.; Bonilla-Mora, V.; Rodríguez-Castro, E.; Leiva-Villacorta, F.; Loría-Salazar, L. Morphological Analysis of Bitumen Phases Using Atomic Force Microscopy. Road Mater. Pavement Des. 2015, 16, 138-152. https://doi.org/10.1080/14680629.2015.1029672.

\section{Author contributions:}

Competing financial interests: The authors declare no competing financial interests. 
Figure 2 Effect of cold temperatures on the surface properties of bitumen. AFM tapping surface topography scans on bitumen at steps (a) $\mathrm{T} 1=25^{\circ} \mathrm{C}$ and (b) $\mathrm{T} 1=-20^{\circ} \mathrm{C}$ during the stepwise cooling sequence and their magnified areas are shown in (c) and (d), respectively. (e)-(f) Corresponding AFM phase images of the same locations as in $\mathbf{a}$ and $\mathbf{b}$, respectively. (g) The enlarged area of $\mathbf{e}$ showing three domains: catana, peri, and para. (h) Magnified view of $\mathbf{f}$, showing five domains at low-temperature in addition to the other three domains in $(\mathrm{g})$.
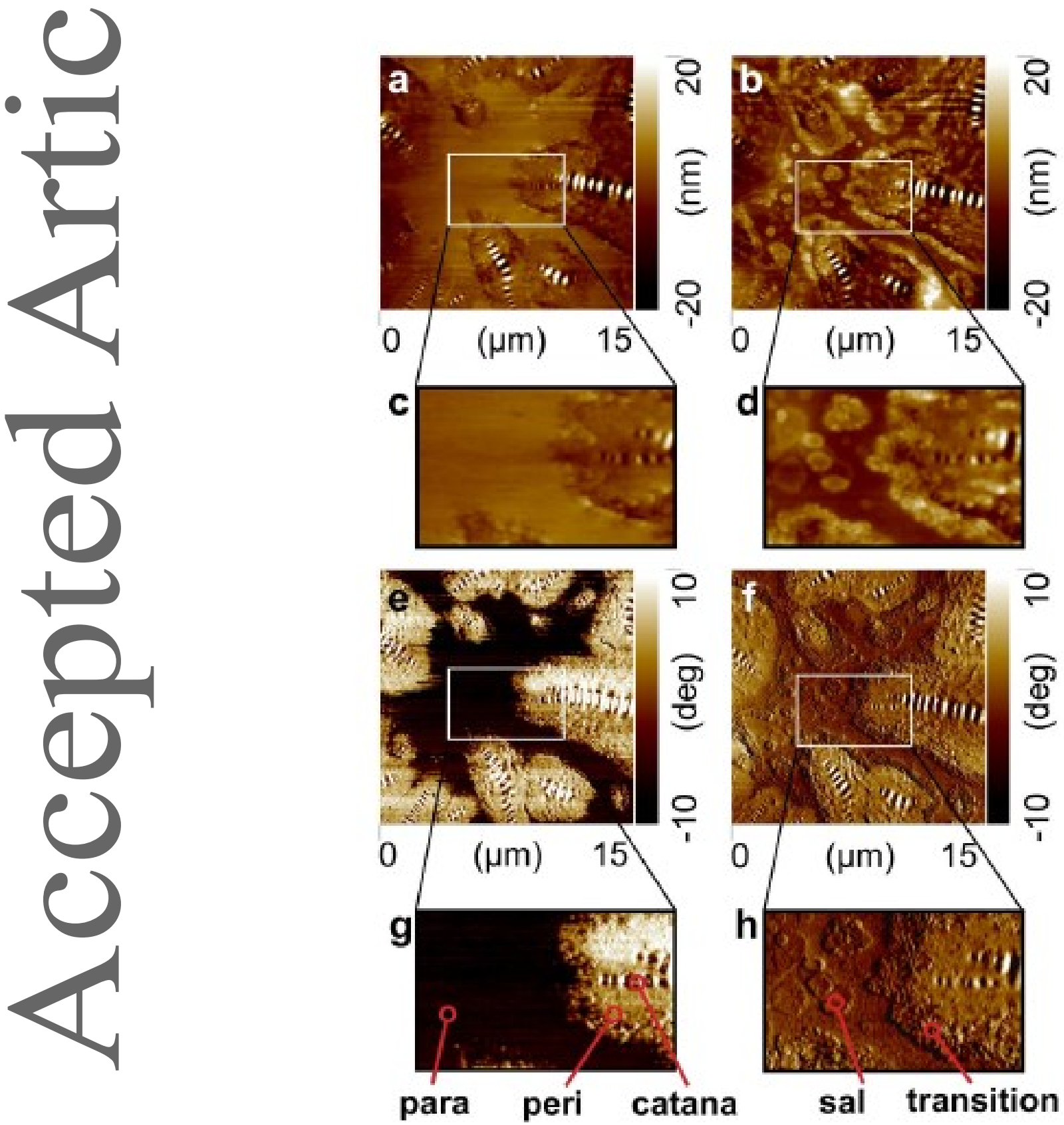

This article is protected by copyright. All rights reserved. 
Figure 3 Effect of temperature on surface roughness in specific domains. AFM topography images at steps (a) $\mathrm{T} 1=25^{\circ} \mathrm{C}$ and (b) $\mathrm{T} 1=-20^{\circ} \mathrm{C}$ of the stepwise cooling sequence. (c) Lines indicate topographies of bitumen at $\mathrm{T} 1=25^{\circ} \mathrm{C}$ (red) and $\mathrm{T} 1=-20^{\circ} \mathrm{C}$ (blue) in approximately the same location. The green asterisk is the zero point of the line profile (Distance $=0 \mu \mathrm{m}$ ). Marked points by circles are the valleys of the catana structures in the vicinity through which the line passes, to show that microstructures shift their position relative to each other as a consequence of the cooling.
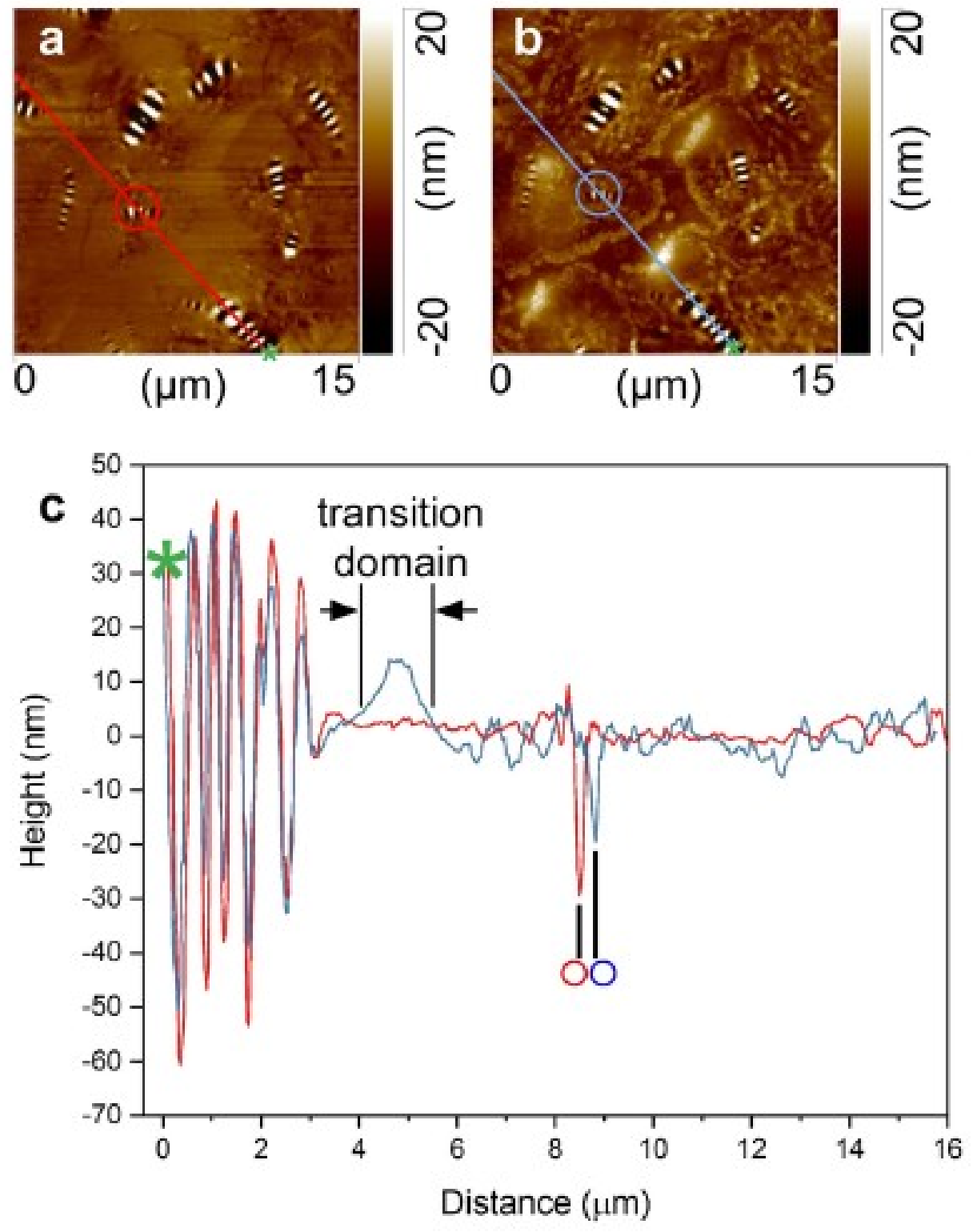
Figure 4 Effect of temperature on bitumen surface domains. Example of AFM phase image at the same location, during the stepwise cooling cycle shown in the Figure $4 \mathrm{~d}$ (right axis) (a) $\mathrm{T} 1=25^{\circ} \mathrm{C}$, (b) $\mathrm{T} 1=-35^{\circ} \mathrm{C}$, and (c) $\mathrm{T} 1=25^{\circ} \mathrm{C}$ (reheated to the initial condition). (d) Sal sub-domain (red), para domain (blue), and transition domain (green) area fractions vs. T1 (- - ) and T2 (-) vs. time. Symbols $\mathbf{\square}, \boldsymbol{\Delta}$, and $\bullet$ each show an independent AFM scan sequence on a fresh sample at the same location in dry conditions, showing qualitatively similar behavior.
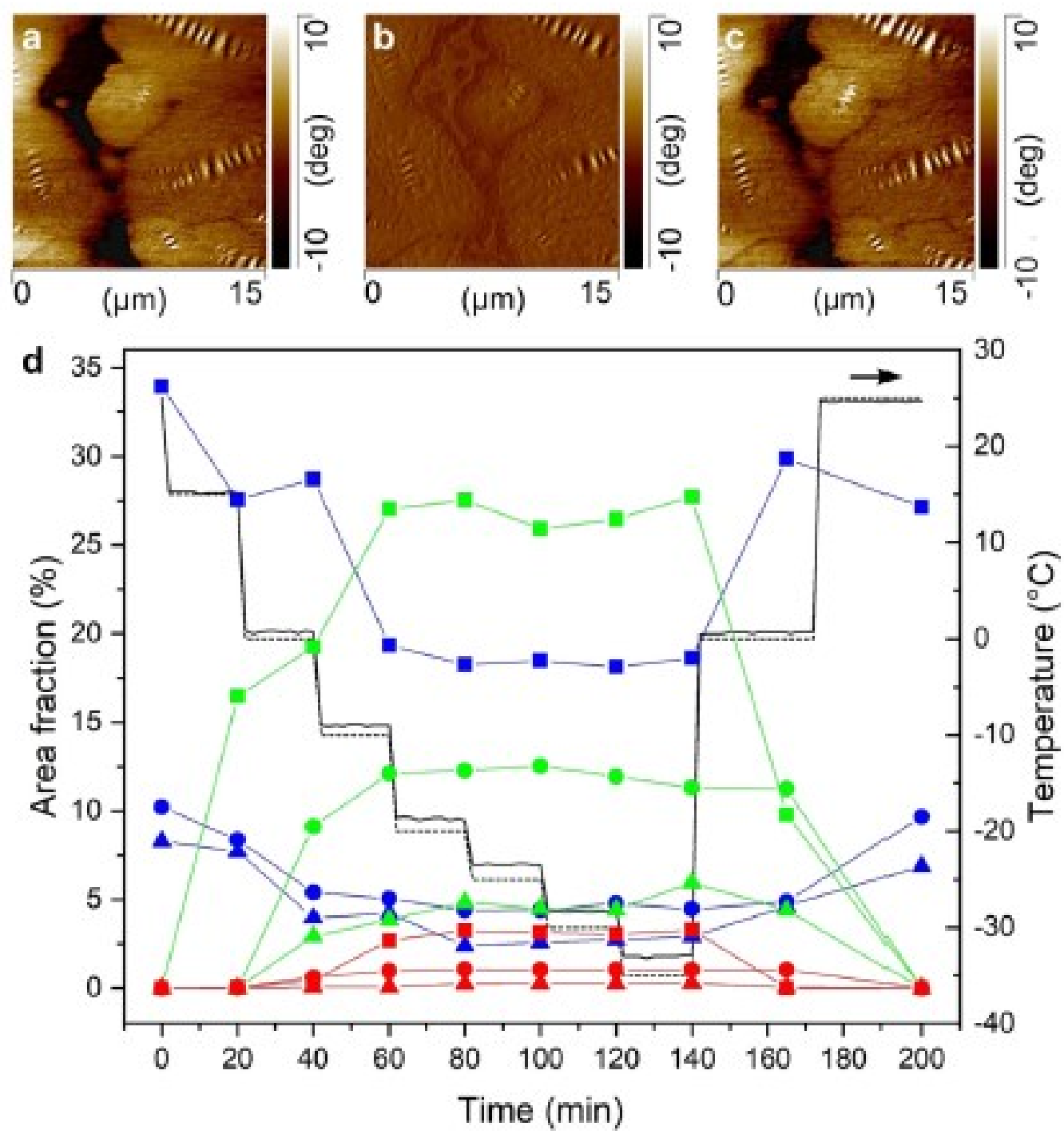

This article is protected by copyright. All rights reserved. 
Figure 5 Effect of the slow cooling rate on the faded boundaries of the bitumen surface microstructure and determination of the chemistry of the transition domain. AFM-IR (a) topography, (b) phase, and (c) IR spectroscopy images for wavenumber $1456 \mathrm{~cm}^{-1}$ at $\mathrm{T} 1=25^{\circ} \mathrm{C}$. (d) topography, (e) phase, and (f) IR spectroscopy images for wavenumber $1456 \mathrm{~cm}^{-1}$ of bitumen at $\mathrm{T} 1=-20^{\circ} \mathrm{C}$ (directly cooled from $\mathrm{T} 1=25^{\circ} \mathrm{C}$ to $\mathrm{T} 1=-20^{\circ} \mathrm{C}$ at a slow constant cooling rate of $\sim-1.5^{\circ} \mathrm{C} / \mathrm{min}$ ). (g) AFM-IR spectra smoothened by Savitzy-Golay function using a polynomial order of five fittings on six neighboring points. Spectra of bitumen at $\mathrm{T} 1=25^{\circ} \mathrm{C}$ (para: orange line, peri: red line; see $\mathrm{b}$ for locations) and $\mathrm{T} 1=-20{ }^{\circ} \mathrm{C}$ (para: cyan line, peri: blue line, transition domain: green line; see e for locations) and the original bulk FTIR spectra at $23^{\circ} \mathrm{C}$, black line. The straight vertical line shows the location of $1456 \mathrm{~cm}^{-1}$ wavenumber.
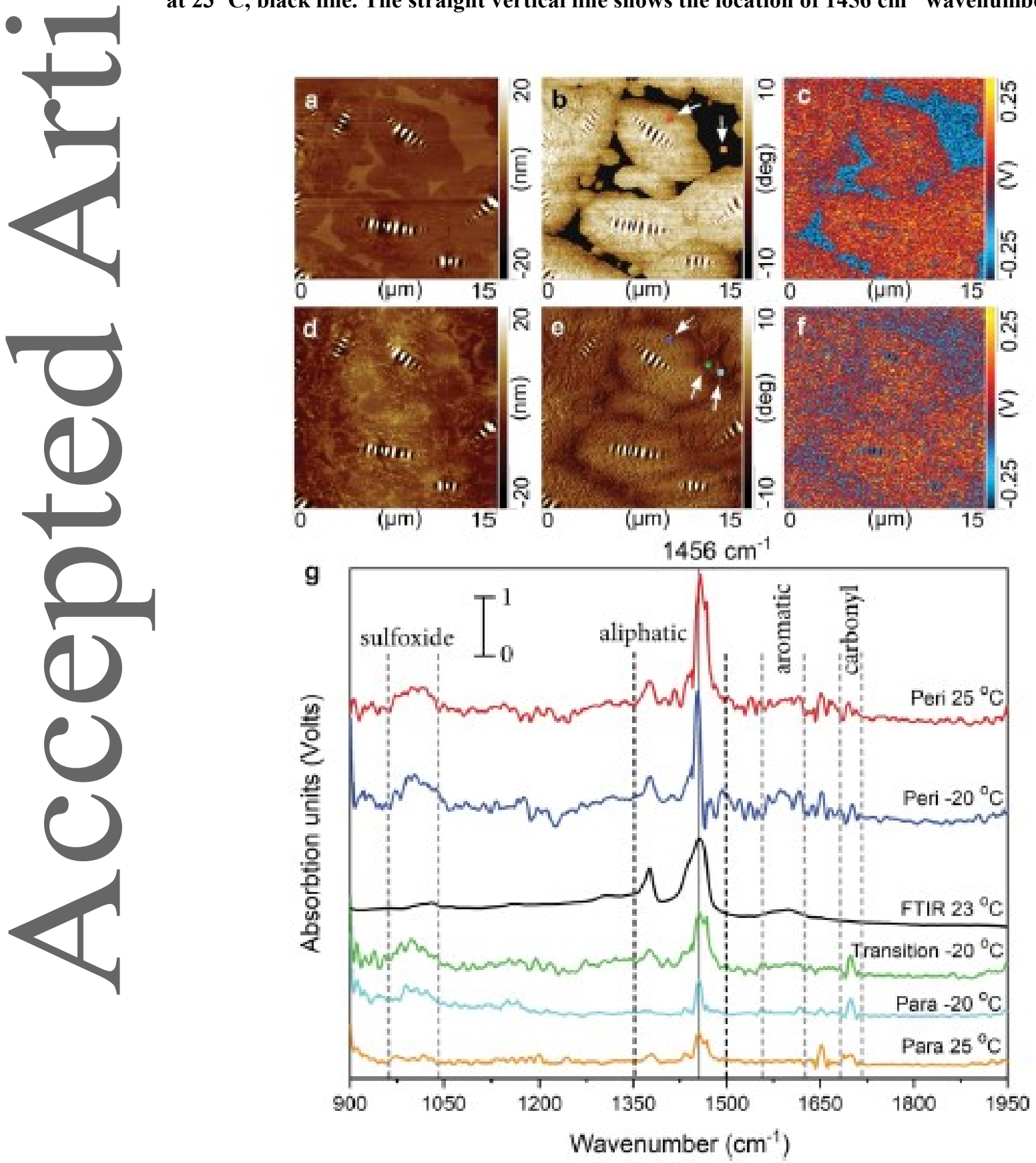

This article is protected by copyright. All rights reserved. 
Table 1 IR index and wavenumber range of the bitumen chemical functional groups based on FTIR and AFM-IR spectra. The availability of chemical functional groups is defined for each fraction of SARA.

\begin{tabular}{|c|c|c|c|c|}
\hline Functional groups & sulfoxide & aliphatic & aromatic & carbonyl \\
\hline Wavenumber limit & $958-1049$ & $\begin{array}{l}1353-1394 \\
1408-1500\end{array}$ & $1546-1626$ & $1690-1710$ \\
\hline Index & $\frac{A_{1030}}{\sum A}$ & $\frac{A_{1376}+A_{1456}}{\sum A}$ & $\frac{A_{1600}}{\sum A}$ & $\frac{A_{1700}}{\sum A}$ \\
\hline $\begin{array}{l}\text { SARA fraction } \\
\text { (availability of the } \\
\text { functional groups) } \\
\text { References: }{ }^{21,57}\end{array}$ & $\begin{array}{l}--- \\
--- \\
\text { Resin } \\
\text { Asphaltene }\end{array}$ & $\begin{array}{l}\text { Saturates } \\
\text { Aromatic } \\
\text { Resin } \\
\text { Asphaltene }\end{array}$ & $\begin{array}{l}\text {--- } \\
\text { Aromatic } \\
\text { Resin } \\
\text { Asphaltene }\end{array}$ & $\begin{array}{l}---- \\
--- \\
\text { Resin } \\
----\end{array}$ \\
\hline
\end{tabular}

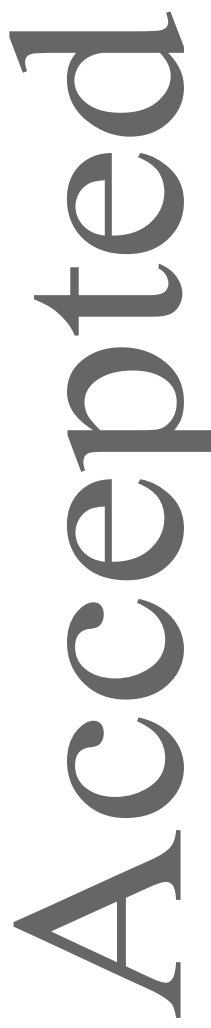

Figure 6 IR indexes of FTIR spectra and AFM-IR local IR spectra of the bitumen surface domains show the concentration distribution of the chemical functional groups in bulk and nanoscale, respectively, as a function of temperature. Functional groups are present around wavenumbers corresponding IR peak values, sulfoxide: $1030 \mathrm{~cm}^{-1}$, aliphatic: $1376 \mathrm{~cm}^{-1} \& 1456 \mathrm{~cm}^{-1}$, aromatic: $1600 \mathrm{~cm}^{-1}$ and carbonyl: $1700 \mathrm{~cm}^{-}$ ${ }^{1}$. Each column bar shows average value with $\min$ and max values for at least three experiments. In cases of peri $25^{\circ} \mathrm{C}$, and para $-20{ }^{\circ} \mathrm{C}$, the bar represents 4 and 5 data points, respectively. FTIR column bar is an average of 32 measurements with a negligible error.

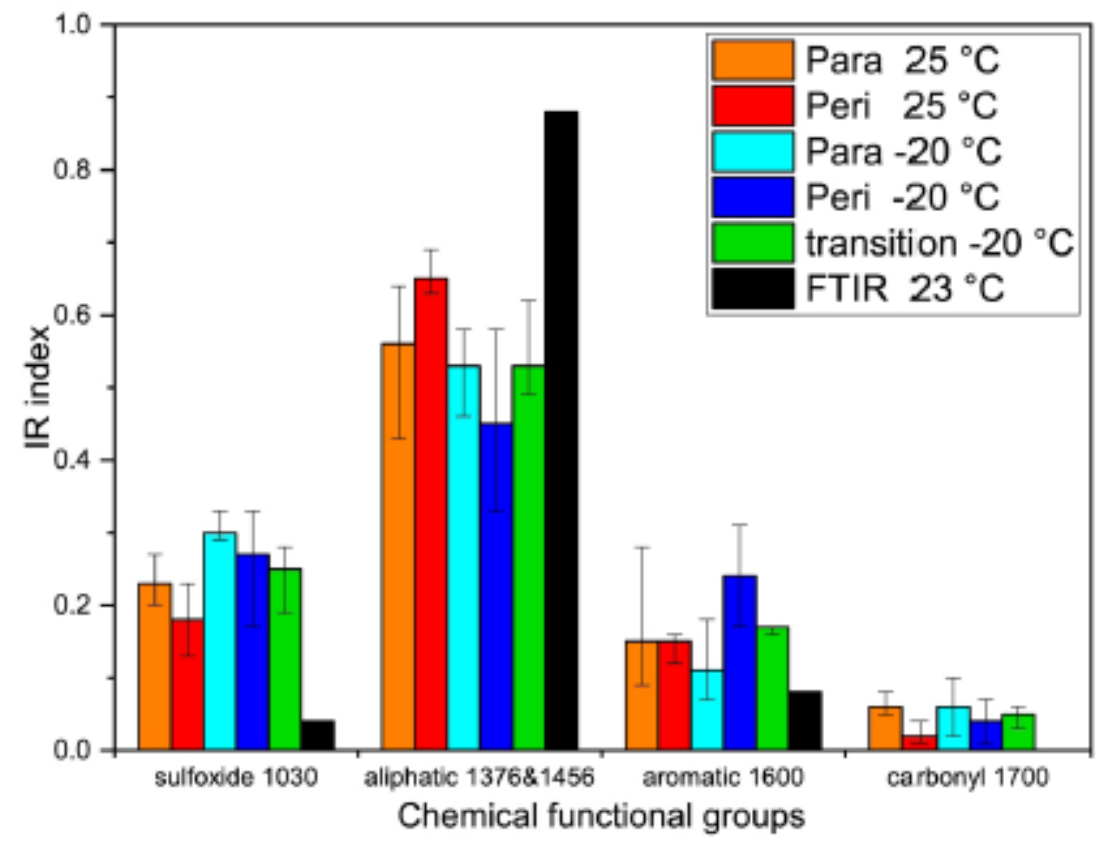

This article is protected by copyright. All rights reserved. 
Figure 7 Coarsening of the para domain and plentiful appearance of the sal sub-domain with a narrow transition domain from very high cooling rates. AFM-IR results showing (a) topography, (b) Phase map (AFM phase), (c) Magnified phase map view of the marked area by the white square (see b), and (d) IR spectroscopy images for wavenumber $1456 \mathrm{~cm}^{-1}$ of bitumen at T1=25 ${ }^{\circ} \mathrm{C}$. AFM-IR (e) topography, (f) phase map (AFM phase), (g) Magnified phase map view of the marked area by white square (see f)and (h) IR spectroscopy images for wavenumber $1456 \mathrm{~cm}^{-1}$ of bitumen at $\mathrm{T} 1=-20{ }^{\circ} \mathrm{C}$ (directly cooled from $\mathrm{T} 1=25$ ${ }^{\circ} \mathrm{C}$ to $\mathrm{T} 1=-20{ }^{\circ} \mathrm{C}$ at an extreme cooling rate of $\sim-90{ }^{\circ} \mathrm{C} / \mathrm{min}$ ). Densely emerged sal sub-domain (see g) with limited transition domain, because of the fast cooling rate.
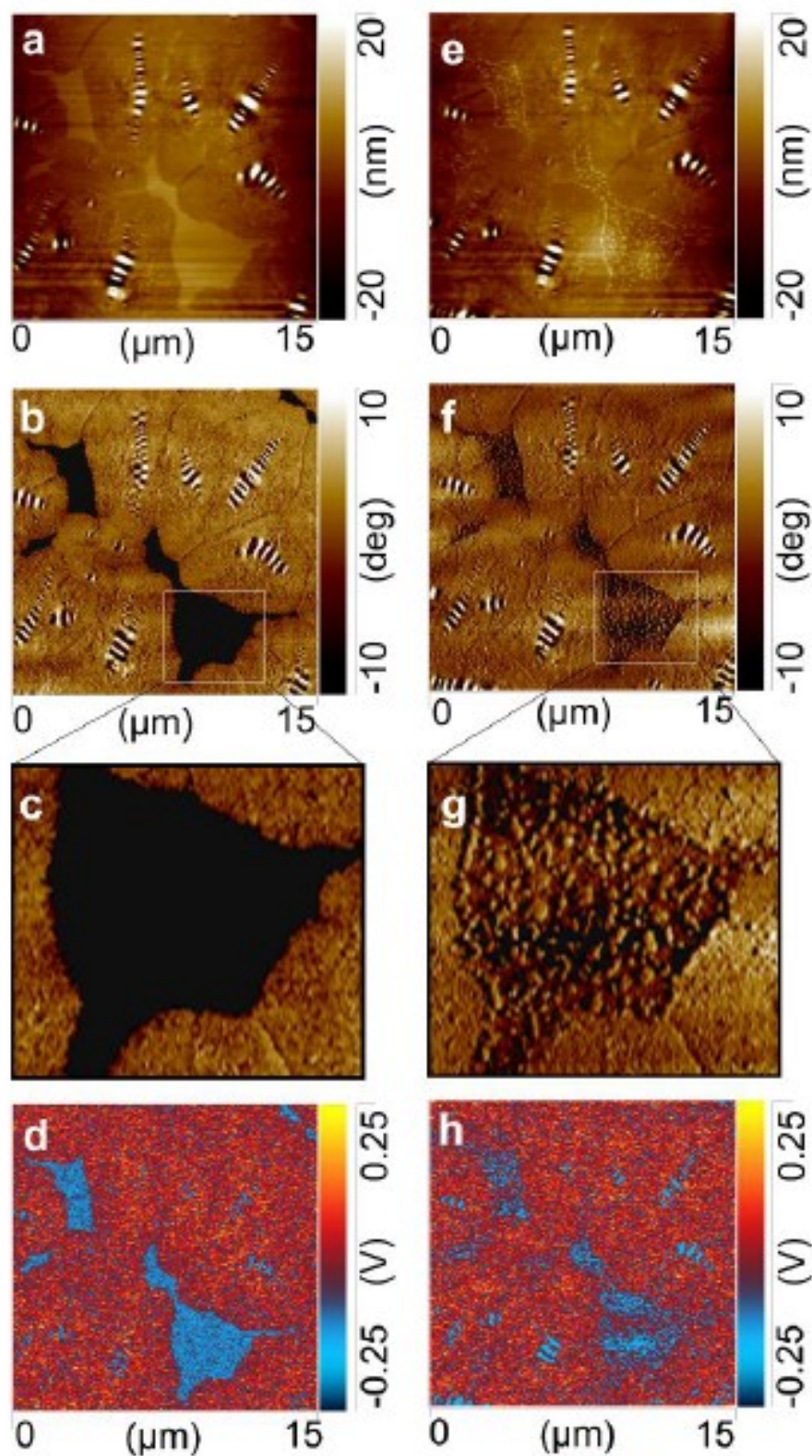

This article is protected by copyright. All rights reserved. 